\title{
Research on the Application of Traditional Auspicious Elements in Modern Graphic Design
}

\author{
Limin Sui ${ }^{1, a}$ \\ ${ }^{1}$ Urumqi Vocational University, Urumqi, Xinjiang, 830002 \\ ${ }^{a}$ email
}

Keywords: Traditional Auspicious Elements, Modern Graphic Design, Application Research

\begin{abstract}
The traditional Chinese culture and art is a unique symbol of art that is formed by the ancestors of our country from the prehistoric spirit of the universe and the creation of life consciousness. The unique life image formed in the process of praying for the reproduction of life, the protection of life and the development of life. China's traditional auspicious culture with the passage of time, historical changes, with the science and technology, the continuous evolution of materials technology, as well as the continuous integration of foreign culture, extension, evolution, the formation of a rich and colorful form of art. Chinese traditional auspicious cultural resources are extremely rich, they in their own development and evolution, both a consistent context, there are rich and colorful style. They are unique and consistent style, showing a unique, deep and attractive national traditions and national spirit, thus forming a unique traditional Chinese art system, this system embodies the wisdom of the Chinese nation for thousands of years the essence, but also Embodies the unique artistic spirit of the Chinese nation.
\end{abstract}

\section{Introduction}

Sui and Tang dynasties, the Chinese auspicious patterns are increasingly perfect, gradually popular. Especially in the Song and Yuan Dynasties, the Chinese auspicious patterns are widely used in architectural painting, ceramics, embroidery, fabric, lacquerware, this time the Chinese auspicious pattern into the development of a high degree of popularity, and even to the "map will be auspicious" To the point. Ming and Qing Dynasties, the Chinese auspicious patterns began to mature. Chinese auspicious patterns are in the form of more colorful, and the use of pattern techniques to be expressed, so that the Chinese auspicious patterns more mature and perfect. As auspicious patterns, auspicious customs, auspicious words spread more far-reaching, but also gradually on the social and cultural impact gradually deepened. Overall, the history of the development of traditional Chinese auspicious patterns, its roots in the original humanities, began in Shang and Zhou, high-speed development in the Song and Yuan Dynasties, to the Ming and Qing Dynasties reached its peak.

\section{The Cultural Connotation of Auspicious Patterns}

Traditional auspicious patterns are unique to Chinese traditional designs, and they can best embody the form of Chinese national spirit and national emotion and national aesthetics. It has profound cultural connotation. Whether in China or abroad, they are based on the development characteristics of their respective nationalities, formed on behalf of the local culture of the traditional auspicious patterns are different, have their own characteristics, but it can not escape the three characteristics of the pattern, that is, Practicality, craftsmanship. Chinese traditional auspicious patterns originated in Shang and Zhou, began in the Qin and Han Dynasties. It is developed in the Tang and Song, mature in the Ming and Qing Dynasties. Chinese traditional auspicious patterns are the most important part of the Chinese folk culture, reflecting the Chinese people in the long-term social life gradually formed a good life for the longing and the pursuit of natural things or social phenomena in the traditional philosophy of faith into Visual patterns, patterns, I believe auspicious patterns can avoid disaster, to bring people Jiqingxiang side. The traditional Chinese auspicious patterns focus on the five themes of "blessing, Lu, Shou, hi, hi", and in the minds of the Chinese people, the auspicious 
pattern has all the good wishes of the people and the longing for the happy life. It is the foundation of Chinese folk culture.

Traditional auspicious patterns in the auspicious rich connotation, the truth of good and the beautiful is a symbol of people pinning a good longing. Auspicious pattern of connotation is an abstract concept, auspicious pattern is the abstract concept of figurative, image. Intelligent Chinese people with rich imagination and associative force, first abstract concepts and specific physical interrelated, and then this real object landscaping, and other mascots combined together, the final effect is that Let people read the abstract concept in the picture. Its special cultural connotation in the graphic design and application through the new form of interpretation, without cumbersome text, ideographic more direct and accurate, in modern graphic design has been more widely used.

\section{The National Style of Traditional Jurchen Culture and the Internationalization of Modern Graphic Design}

National style is the embodiment of national character, and national character is the accumulation of history, is due to the formation of human development by the natural and social living environment limitations and constraints, will inevitably produce cosmology, outlook on life and cultural traditions, which is the special Sex, reflected in the design work has a distinctive national character, this national character is reflected in the design of the ideological content, but also reflected in its artistic expression. Designers of different nationalities are bound to consider the unique cultural background of their nation when designing their products and daily necessities. Therefore, the products designed by the designers of different nationalities will have a common thing (form or connotation) It can make people appreciate the characteristics of their nation. The culture and art of the Chinese nation is a rich treasure house, has a profound inspiration and reference for graphic design. And for the rich national cultural resources, we can multi-level, multi-angle to re-understanding, and then explore.

China's five thousand years of civilization development, whether it is palace art or folk art, whether it is literati painting or religious painting, through the ancient painters, artists, craftsmen, people's creative practice, accumulated a large number of rich and varied artistic expression and expression. From the Neolithic pottery to the bronze period of the Shang Dynasty, from the Warring States period of lacquerware, silk painting to the Han Dynasty carvings, stone, from the Tang and Song paintings to the Ming and Qing Dynasties porcelain, and folk widely circulated paper, woodcut New Year paintings, Architectural ornaments, costumes, masks, etc., fully embodied or grand or smart, or simple or refined, or neat or extensive, or warm or gorgeous, or simple or luxurious and other means. Whether it is a penny hibiscus of the Chinese painting ink, or plate engraved round decorative patterns: whether it is exaggerated folk paper-cut, or colorful woodcut New Year paintings, all of which are all for modern graphic design provides a rich form of expression and schema language The These, for today's mechanical tools, computer technology to bring the performance of monotonous rational tendency, for the modern means and the wisdom of the coordination of the way, will play an important balance. As the famous American sociologist John \# Naisi bit pointed out in the information age, once the high technology and high feelings of loss of balance, there will be annoying results, and the rich and colorful human and national culture Just with the computer community balance. Chinese traditional painting and arts and crafts of the aesthetic taste of advocating is not like, moved to Miaode, outside the good fortune, in the heart, do not rigidly adhere to the moment to see, and is committed to express the author's image. The aesthetic characteristics of this freehand, breaking the reality of the object of people free imagination and creation of imprisonment, beyond the boundaries of nature and reality, to create a real world does not exist in the fresh and dynamic art. With the scatter perspective, move the scene or multi-dimensional method to create the artistic image, whether it is the snake's first Fuxi female worm, or wingless and the Dunhuang Flying, and the lion's head antlers snake's eagle claw totem One dragon, a lot of ancient art treasures still still flashing the magic of surrealist aesthetic taste. Facts have proved that China's unique aesthetic spirit is to stimulate the modern graphic design inspiration for the inexhaustible source. In the process of drawing on the use of national culture, 
whether it is a reference to the performance method or a reference to the image element, whether it is a reference to the thinking method or a reference to the aesthetic spirit, must be from the modern design point of view to start again Look at the traditional culture of the original object, so as to achieve new experiences and new discoveries. China's modern design to integrate into the international modern design stage, with the design community to better communicate, communication, must maintain national characteristics at the same time, the use of international common design language. Modern design languages include modern design theory, modern design concepts, modern design thinking methods and modern design forms of expression. Modern design language changes with the development of the times, we must keep abreast of and grasp the dynamics and trends of modern design. The research and application of modern design language is an important way for Chinese design to go to the world and get recognized by the world culture.

\section{Application of Chinese Traditional Auspicious Pattern in Modern Graphic Design}

Auspicious patterns are in the use of modern graphic design in China a lot of examples, and now the most representative than the 2008 Beijing Olympic Games logo. From the beginning of the preparation of the Olympic Games, to the formal completion of the Olympic emblem, each part shows the characteristics of China, by the world's unanimous praise. Olympic emblem is by the composition of the Olympic rings, the shape of the traditional Chinese folk arts and crafts like the "Chinese knot", but also like a tai chi humanoid. "Taijiquan is the quintessence of China, the whole pattern of flowing water, harmony and vivid, full of sports, a symbol of the people of the world unity, cooperation," the Chinese people are symbolizing the good luck, but also reflects the Chinese people are heart-hearted, solidarity; Exchange, develop, work together to create a profound meaning of the new century. Of course, there are other examples, such as: Bank of China is the representative of China's financial business, requiring the embodiment of Chinese characteristics. Bank of China's logo using the Chinese ancient money and the "middle" as the basic shape of the word, the shape of the ancient money is round and shaped frame design, the middle of a square hole, up and down with a vertical line, a "medium" shape, To the round, to the economy-based, gives the feeling is simple and clear, stable, easy to identify, meaning profound, quite Chinese style. Bank of China this mark has been able to leave people so deeply impressed, I think this is still due to the people have been symbolic wealth of the shape of the understanding of the bar. China Telecom's logo is the traditional Chinese style of the text and the "Chinese" as the basis for the word, through the development and changes in the formation of three-dimensional three-dimensional space pattern, its meaning is extending in all directions of the communications network, a symbol of China Telecom from time to time, , The image of the expression of the characteristics of China Telecom: technology, modern, transmission, speed, development, the decorative effect of this pattern is relatively strong, and with Chinese characteristics and sense of the times, it can be said that the use of traditional Chinese culture is very modern A sense of the classic. Chinese traditional auspicious patterns are as a special "symbol element" is with the modern graphic design has more and more intersection. It is a concise image to express a certain meaning, and with people's symbol recognition, association and other thinking ability, to convey specific information. People with the meaning of the rich traditional auspicious patterns in the modern graphic design, through the re-creation of art, in a beautiful form to express deep inside the good things yearning, its aesthetic taste and habits deeply penetrate and rooted in people Of the ideology, people because of understanding and love, because of inheritance and promote. The traditional Chinese auspicious patterns are gorgeous artistic charm to attract more people's attention and concern, its form of beauty and internal metaphor combined with the way to the modern graphic designers with unlimited creative inspiration and creative source.

\section{Conclusion}

Now is the Internet age, the distance of the world, but the length of the heart and heart, the earth has become a village, our design works through a variety of modern means of widespread and rapid spread, our cultural exchange also It is very frequent and effective. Only based on the contemporary, 
deepen our excellent traditional culture, our design will be more and wide road, will occupy a place in the international community. As a designer, we have to use our way to make our excellent traditional culture become the foundation and cornerstone of modern graphic design, so that excellent traditional culture through modern graphic design works spread to the world, so that the traditional culture to our society and tomorrow.

\section{Acknowledgements}

Fund Project: World Bank Project Urumqi Vocational College Subproject "Altay Rock Painting Tourism Derivatives R \& D"

Item No.: 2016XY005

\section{References}

[1] Ma Li. Chinese traditional auspicious cultural patterns [J]. Thinking and wisdom, 2013 (03)

[2] Chen Lili. The Expression of Auspicious Culture in Spark Design at the End of Qing Dynasty and the Beginning of the Republic of China [J]. Journal of Packaging, 2012 (01)

[3] He Yixing. Modern design of the auspicious culture of the inheritance [J]. Art and design (theory), 2011 (04)

[4] Zhao Qili. Auspicious culture in the jewelry [J]. China Gold Jewelry, 2008 (01)

[5] Wu Guanying. Auspicious Culture and Olympic Mascot Design [J]. Design Art, 2008 (04)

[6] Ma Zhiyuan. On the auspicious culture of the spirit of the mirror and artistic expression [J]. Art, 2007 (04) 